\title{
A Psycholinguistic Framework for Diagnosis and Treatment Planning of Developmental Speech Disorders
}

\author{
Hayo Terband $^{\mathrm{a}}$ Ben Maassen $^{\mathrm{b}}$ Edwin Maas $^{\mathrm{c}}$ \\ a Utrecht Institute of Linguistics-OTS, Utrecht University, Utrecht, The Netherlands; ${ }^{\mathrm{b}}$ Centre for Language \\ and Cognition (CLCG) and University Medical Centre, University of Groningen, Groningen, The Netherlands; \\ ${ }^{c}$ Department of Communication Sciences and Disorders, Temple University, Philadelphia, PA, USA
}

\section{Keywords \\ Speech development $\cdot$ Speech disorders · Differential diagnosis · Treatment planning}

\begin{abstract}
Background: Differential diagnosis and treatment planning of developmental speech disorders (DSD) remains a major challenge in paediatric speech-language pathology. Different classification systems exist, in which subtypes are differentiated based on their theoretical cause and in which the definitions generally refer to speech production processes. Accordingly, various intervention methods have been developed aiming at different parts of the speech production process. Diagnostic classification in these systems, however, is primarily based on a description of behavioural speech symptoms rather than on underlying deficits. Purpose: In this paper, we present a process-oriented approach to diagnosis and treatment planning of DSD. Our framework comprises two general diagnostic categories: developmental delay and developmental disorder. Within these categories, treatment goals/targets and treatment methods are formulated at the level of processes and rules/representations. Conclusion: A process-oriented approach to diagnosis and
\end{abstract}

\begin{tabular}{ll}
\hline KARGER & ( 2019 The Author(s) \\
Published by S. Karger AG, Basel Oparger \\
E-Mail karger@karger.com & This article is licensed under the Creative Commons Attribution- \\
www.karger.com/fpl & NonCommercial-NoDerivatives 4.0 International License (CC BY- \\
NC-ND) (http://www.karger.com/Services/OpenAccessLicense). \\
Usage and distribution for commercial purposes as well as any dis- \\
tribution of modified material requires written permission.
\end{tabular}

treatment planning holds important advantages, offering direct leads for treatment aimed at the underlying impairment, tailored to the specific needs of the individual and adjusted to the developmental trajectory.

(C) 2019 The Author(s)

Published by S. Karger AG, Basel

\section{Introduction}

Speech constitutes the primary channel of human social interaction; yet speaking can be considered the most complex skill humans perform. Although most children acquire speech relatively automatically and with little difficulty, some children struggle with the acquisition of speech production skills and require sustained and intensive treatment [1]. Children with speech disorders are at increased risk of social-emotional and behavioural problems $[2,3]$, as well as of delayed development of language, literacy, and other academic skills [4]. These issues may limit employment and occupational opportunities in adulthood $[5,6]$. Accurate diagnostic methods and effective intervention programmes are thus of crucial importance to limit the short- and long-term impact of developmental speech disorders (DSD) on the individual. 
Unfortunately, differential diagnosis and treatment planning of paediatric speech disorders remains problematic. Existing systems of diagnostic classification comprise a set of theoretically grounded categories (definitions) that are associated with a symptom complex and start from the assumption that the categories can be differentiated by a diagnostic marker. A number of different systems for the classification of paediatric speech disorders have been proposed throughout the years [for an overview, see 7], in which subtypes are differentiated based on their distal or proximal cause. The predominant systems at the moment are Shriberg's Speech Disorders Classification System (SDCS) $[8,9]$ and Dodd's Model of Differential Diagnosis (MDD) $[10,11]$. The SDCS is a classification based on the presumed aetiological background of the speech impairment and consists in its most recent form of three main categories divided into eight subcategories:

- Speech delay (SD; distal causes)

- Genetic

- Otitis media

- Psychosocial

- Motor speech disorders (MSD; proximal causes)

- Apraxia (childhood apraxia of speech; CAS)

- Dysarthria (developmental dysarthria; DD)

- Not otherwise specified (MSD-NOS)

- Residual speech errors

- /s/

- /r/

The basic idea behind the SDCS is that there are identifiable causes and that there are one-to-one relationships to specific speech symptoms [9]. A fundamental problem of the SDCS is that the classification system is inconsistent in specifying the levels of explanation across categories. In principle, the categorisation is based on the presumed aetiological background $[8,9]$, but the two subcategories of residual speech errors are purely symptomatic descriptions at the behavioural level. Additionally and more importantly, the other subcategories of SD and MSD represent factors on different levels of explanation, i.e., genetic, otological, neurological, and psychological. Multiple factors and multiple levels could be involved in a single case, and their exact role and weight in causing the speech symptoms remains unclear. Moreover, the clinical characterisations of the diagnostic categories consist of a terminology that refers to speech production processes, but how the aetiology is related to the processing deficit is not specified. Thus, the SDCS can be characterised as a hybrid classification system that has the ambition to encompass all speech sound disorders. In its current state, however, the complexity of this system due to the different levels of causation involved, and the underspecification of the relation between levels, form serious obstacles to clinical use.

The MDD $[10,11]$ is based on Stackhouse and Wells' [12] Psycholinguistic Framework, a modular psycholinguistic model of speech production and development. The categorisation consists of (sub)groups that are based on the psycholinguistic level of the presumed core deficit, the processing level that would be affected:

- Phonological disorder (PD; phonemic level)

- Phonological delay

- Consistent

- Inconsistent

- Phonetic articulation disorder (PAD; phonetic level)

- Developmental apraxia of speech (DAS; motor level; planning and programming)

In contrast to the SDCS, the MDD thus revolves around the proximal cause of the different disorders (the processing level) and it does not make claims about their possible more distal causes (neurobiology or aetiology). Although this system is consistent in terms of definitions and level of description (the psycholinguistic level of processing), this is only the case for the main categories, whereas subcategories of PD are defined based on symptomatology.

Apart from these specific issues, both classification systems suffer the same problem in that the relation between different levels of causation, in particular the psycholinguistic and the behavioural level, remains underspecified. Diagnostic markers that are both specific and sensitive have not yet been identified for all categories that are differentiated (e.g., PD, CAS/DAS, and MSDNOS). Regardless of the theoretical basis, the definitions of the disorders in these systems refer to speech production processes. A variety of intervention methods for helping children with DSD have been developed, aiming at different parts of the speech production process, such as lemma selection, sequencing speech sounds and syllables, and planning/programming and execution of articulatory movements. Clear criteria for determining which treatment is the most suitable for an individual child, however, are lacking. Thus, whereas the definitions of the different disorders tend to refer to (hypothesised) underlying deficits or causes, the clinical procedures for differential diagnosis are not aimed at these definitions [see also, e.g., 13-17, where similar conclusions were presented with respect to the taxonomy of adult dysarthria]. The current diagnostic instruments consist of tests that measure knowledge and complex skills, such as sentence formulation, vocabulary, picture and colour naming, and 
phoneme inventory. Classification comprises the assignment of a diagnostic category based on a behavioural description and symptomatology. This classification procedure does not provide sufficient direct information about the underlying processes and does not allow specification of the gradual involvement of different speech production processes.

At the genetic level, a variety of abnormalities have been linked with developmental speech and language disorders (e.g., mutation of FOXP2 [18, 19], mutation of GRIN2A [20], and microdeletion of BCL11A [21]). Although the progress in this area is promising, the associated symptomatology is highly heterogeneous and often encompasses speech and non-speech motor functions, expressive and receptive language functions, and cognitive functions such as short-term memory and sequencing more in general $[18,22-26]$. Direct links between genotype and phenotype have yet to be established [25, 26]. Also at the neurobiological level, few specific underlying deficits have been established for speech disorders other than perhaps those affecting peripheral sensory and motor systems. The link between particular neurobiological findings (e.g., atypical development of the left corticobulbar tract [27] and a thinner corpus callosum [28]) and cognitive and sensorimotor processes and behavioural performance remains to be explicated. Furthermore, in typical clinical settings, such information about the underlying genetic or neurobiological pathology is rarely available. Thus, although research on the genetic and neurobiological underpinnings of DSD may hold promise for our understanding and, in the long term, for clinical purposes, at present such research does not provide insights or specific suggestions to speech-language pathologists for diagnosis or for treatment planning for speech therapy [29]. In contrast, a focus on the underlying psycholinguistic processes has clear implications for diagnosis and treatment, as we outline further below.

The fundamental diagnostic problem is that different levels of causation in interaction underlie the speech disorder, and that at none of these levels in isolation, specific and sensitive diagnostic markers for diagnostic classification can be found. Due to the interactions between levels, there is a large overlap of symptomatology between categories and a large heterogeneity within categories. According to the 2004 model of Bishop and Snowling [30], four levels of causation, or four levels of aggregation, can be distinguished that are involved in developmental disorders. The first, aetiological level concerns the genetic constitution of the individual and environmental factors, which together determine the unfolding of the neu- rological architecture at the second, neurobiological level. The brain does not develop according to an exact predetermined blueprint, but is continuously adapting to biological and behavioural (environmental) circumstances. An example would be the communicative activity level of an infant. More active infants tend to elicit more communicative responses from the carer than do more passive infants. The third level is the cognitive and sensorimotor, or psycholinguistic, level describing the processes that underlie the fourth, behavioural level.

As we have argued before, core impairments at different levels of speech development and in different parts of the speech production chain cannot be clearly distinguished from each other at the behavioural symptom level alone, but they need an understanding of the complex interactions between causation levels [31-34]. Many examples have shown that different disorders may show similar symptoms $[17,35]$, but computer simulations have also exemplified that a specific underlying deficit can produce symptoms on (apparently) different levels or domains [36]. Thus, behavioural symptoms are often multi-interpretable at the cognitive and neurobiological level. For example, specific phoneme substitution errors (behavioural) can often be analysed in phonological terms as feature substitutions or in speech-motor terms as articulatory simplifications or as sequencing errors (all three cognitive). Likewise, specific deficits at the neurobiological or cognitive level, if they can be determined at all, can result in a variety of behavioural symptoms. Thus, diagnostic classification requires assessments at different levels of causation and some description of the interaction between levels.

A good example of this basic challenge is the history of the dispute on the core definitions of CAS/DAS. The comprehensive 2007 ASHA Technical Report [37] noted that " $[w]$ hereas some of the definitions of CAS reviewed by the Committee view the core problem as one of planning and programming (cognitive level) the spatiotemporal properties of movement sequences (behavioural level) underlying speech sound production, others propose that the deficit extends to representational-level (cognitive) segmental and/or suprasegmental units in both input processing and production" (p. 4). The ASHA Technical Report has had the effect of enhancing consensus on its definition of CAS as a "core impairment in planning and/or programming spatiotemporal parameters of movement sequences" (pp. 3-4) and, currently, researchers seem to have agreed on this description of processes or proximal causes underlying CAS. Thus, the report clearly makes a choice here at the cognitive and senso- 
rimotor level. The basic problem is how to develop test procedures such that processing and representational deficits can be distinguished. Note that all test procedures make use of behavioural measures, not only assessment of symptoms, but also cognitive tests. The latter are based on behavioural assessments under strict experimental and test administration procedures; also functional brain imaging tests make use of presenting the subject with a task to elicit behaviour such that brain activity can be interpreted.

The high variability and broad spectrum of symptoms in DSD form a major challenge for clinical management and research. Effective differential diagnosis therefore requires a theoretically grounded process-oriented approach focusing on clearly defined underlying deficits (whether cause or processes) rather than classification based on symptoms. Instead of searching for homogeneous groupings of overt speech symptoms and subsequently trying to identify a common cause (whether proximal or distal) one should start with what can be clearly defined. Although the symptomatology and aetiology are not completely clear, there is a solid theoretical basis that allows us to precisely describe specific core problems in terms of psycholinguistic processes $[33,34]$. To identify underlying deficits, one must thus start with a model of the cognitive and sensorimotor operations involved, from which specific hypotheses of speech symptoms are derived [33,34] [see also 12, 38]. A focus on processes instead of cause (aetiology) has the advantage that it provides direct information for treatment. In this paper, we present a theoretically based framework for process-oriented diagnosis and treatment planning of DSD.

\section{An Integrated Psycholinguistic Model of Speech Processing}

The starting point of our framework is an integrated model of the cognitive and sensorimotor functions involved in speech production and perception (Fig. 1). A variety of models of speech processing have been presented over the years [e.g., 39-46]. Each model has its own specific approach, scope and theoretical basis and the scientific discussion on which model gives the best account of all the different speech phenomena traditionally revolves around the differences between models. Whereas the scientific endeavour tends to focus on what we do not know, what we do know is far more important for clinical practice. From this perspective, it can be noted that the

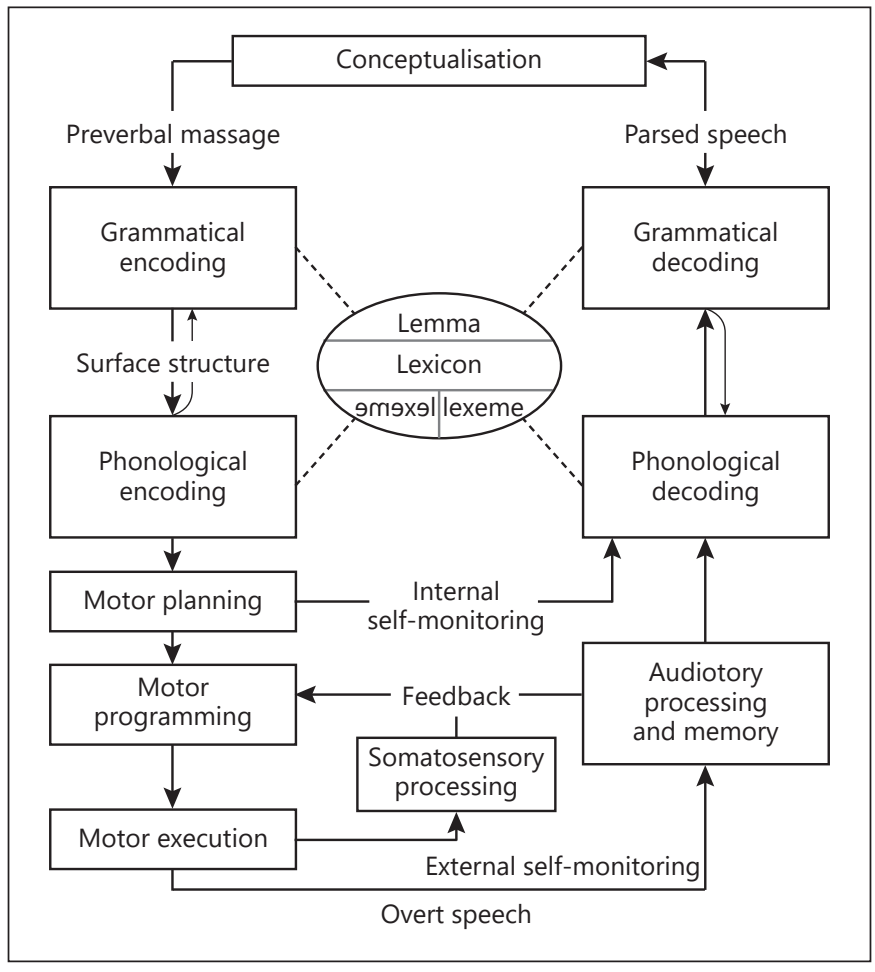

Fig. 1. Adult model of speech processing $[33,34]$ (adapted from Levelt $[39,51]$, Van der Merwe [40, 50], and Guenther [45, 53]), displaying the sensorimotor and memory functions involved in speech production and perception.

different models show important similarities and overlap [see also, e.g., 31, 33, 34, 38, 47].

Similar to any model of complex motor performance, all models of speech processing first and foremost adopt a cascade-style hierarchy of control in which the output of one process forms the input of the next processing level [e.g., 39-46, 48-52]. Leaving out all the details of dispute and differences in scope between models, speech production is preceded by a language process of sentence formulation, in which lemmata are retrieved from the lexicon and inflected and sequenced in a grammatical phrase to match intended concepts, and stored in a shortterm memory buffer (grammatical encoding) [e.g., 39, 51]. Speech production models then start with the word forms (lexemes) retrieved from the lexicon, which forms the input for phonological encoding, in which the sensorimotor targets that constitute the speech sounds or syllables are selected and sequenced in a phonological phrase of linguistic/symbolic units, and stored in a short-term memory buffer [e.g., 39-41, 49-51].

The next stage, motor planning, comprises the selection and sequencing of the articulatory movement goals 
that would produce these targets [e.g., 40-42, 48, 50], and the adaptation of these goals to the phonetic environment (e.g., coarticulation) $[40,50]$. During the subsequent stage, motor programming, the motor plans are then implemented in muscle-specific motor programmes [e.g., $40,43,45,48,50,53]$, taking into account articulatory context, sensory information, and (meta)linguistic requirements (e.g., speech rate, prosody, and prominence) $[40,50]$. Finally, the constructed neural signals that constitute the motor programmes are sent to the peripheral systems and executed, resulting in the actual movements of the articulators (motor execution) [e.g., 40, 43, 45, 48, $50,53]$.

During speaking, these stages form an ongoing process that is monitored continuously at several levels. This selfmonitoring is based on both internal and external feedback (Fig. 1). Internal feedback is used during motor planning to avoid, for example, that erroneously planned speech movements are executed [e.g., 39, 51, 54]. External feedback comprises both fast somatosensory and slow auditory monitoring and provides current information about the state and position of the articulatory organs (such as position, movement direction, and speed) as input for motor programming [e.g., 40, 43-45, 50, 53]. External feedback is further used to monitor the produced speech on the motor programming, phonological, and higher linguistic levels [e.g., 26, 27, 38, 41] and can be used for ongoing adaptation of articulation and error correction [e.g., 43-45, 53].

The adult speech production system is very robust. The different processes and representations are highly overlearned and the system is highly redundant. In case of acquired deafness, for example, speakers continue to be intelligible despite the fact that auditory self-monitoring is completely disabled. The situation is different, however, during speech acquisition in infants and children. The different cognitive and sensorimotor functions are not pre-specified in the infant brain, but they develop gradually into the adult system [55-57]. The different functions and representations develop simultaneously and influence each other during development [e.g., 36, 58].

However, also in the adult speech production and perception system, the different parts of the processing chain are not fully independent. The mutual dependence between processes mainly expresses itself in the case of disruptions. In the adult model, two types of interaction can be distinguished: direct and indirect. With direct interaction, we mean that processes are dependent on input received from other processes. Degraded input from one specific impaired process can lead to problems at the subsequent processing level (which may itself be intact). For example, difficulties in phonological encoding may affect speech motor control processes and thus cause (sensori) motor symptoms [e.g., 49]. Indirect interaction refers to adaptive and compensatory mechanisms. If some part of the system suffers an impairment, the system will try to adapt to the deviant circumstances and/or compensate for the impediments. One simple way in which the system can adapt is by slowing down the speech rate. A slow speech rate is a general characteristic of MSD irrespective of the underlying deficit. In many cases, it does not constitute a primary symptom but rather acts as a compensatory mechanism to make the control task easier $[17,59]$. A clear example of adaptation and compensation mechanisms on a functional-cognitive level can be seen in people with anatomical deformities of the articulatory organs, such as glossectomy [60-65] or dental occlusions and prostheses [66-69].

In the case of an impairment in one of the processes or representations in children, the interaction between the different parts of the system gets an extra dimension. A specific underlying impairment on one level or domain also affects the development on adjacent levels or domains $[14,36,70-72]$. Due to this developmental interaction, the potential influence of primary deficits on adjacent processing levels and of adaptive and compensatory mechanisms is even stronger. A primary impairment at the acoustic-perceptual level can, for example, cause the phonological representations to be incorrect or underspecified. This could in turn lead to a deviant and incomplete phonological system, primarily because it had to learn from degraded input. Similar observations have been described in children with a cleft palate, who often develop specific articulation patterns to compensate for their deficit [73-75]. These compensatory articulation patterns may persist after the cleft has been surgically repaired, causing problems in the development of the children's phonological system [e.g., 73, 74, 76]. Another example is the correlational evidence that suggests that poor motor control in CAS is associated with poor development of the lexicon, the phonological system, and auditory processing $[77,78]$.

As a result of these interdependencies between the different levels of speech development and different parts of the speech production chain, overlap of symptoms in paediatric speech sound disorder is the rule rather than the exception, which has frustrated attempts to find single diagnostic markers for differential diagnosis. This interdependent nature of the developing speech processing 
system means that the idea of finding single diagnostic markers is fundamentally problematic and that attempts to do so are unlikely to be fruitful. As Bishop [55] argued in the context of specific language impairment already more than 20 years ago, the neuropsychological principle of double dissociation in the study of acquired disorders in adults does not apply to developmental disorders. Developmental disorders are characterised by associations between functions rather than dissociation. Differential diagnosis and treatment planning therefore require a different approach than classification based on overt speech symptoms only. Along this line, Maassen [25] presented a multi-level, multi-factorial description of the underlying deficit of CAS.

\section{Process-Oriented Diagnosis and Treatment Planning}

The multi-factorial nature of developmental disorders means that effective diagnosis and treatment planning require a dynamic, process-oriented approach aimed at describing the development of underlying processing deficits to characterise disorders $[31,32,36]$. Based on the integrated model of speech processing presented above (Fig. 1), we propose a framework for process-oriented diagnosis and treatment planning of DSD (Table 1). Two essential elements of our framework are that it comprises general diagnostic categories within which specific treatment goals/targets are formulated at the level of processes and representations.

\section{General Diagnostic Categories}

The framework that we propose distinguishes two general diagnostic categories labelled developmental delay and developmental disorder. The division between these categories is based on fundamental differences in the general characterisation of delayed versus deviant speech development [79-82]. These differences are informative for both the treatment goals/targets and the choice of the treatment method (the design of the treatment programme; the choice and planning of exercises and activities). In the case of developmental delay, development follows the typical pattern, but is delayed. The speech difficulties that the child experiences are not unusual and are also commonly experienced by children with typical development, but they are unusual for the age. Development can also be delayed in the case of developmental disorder; however, essential for the latter category is that development does not follow the typical pattern. Speech difficulties occur that are not usual during any stage in typical development. The different characteristics of the developmental trajectories demand a fundamentally different approach in terms of treatment and thus importantly serve to direct the choice of the treatment goals/ targets and methods.

\section{Treatment Goals/Targets at the Level of Processes and} Representations

The goal of the speech acquisition process is to form the different components of the speech production chain as they exist and function in the adult system (Fig. 1). What we propose with the current framework is that when problems are encountered during speech acquisition, the goals/targets for treatment are defined in terms of these same components. In other words, the possible treatment goals/targets correspond to the processes and rules/representations that are presented in the speech production model in Figure 1. Leaving the language processes aside, the framework differentiates four processing processes and three monitoring processes. The framework further contains a set of phonological rules and two representations that are used by the different processes. A short overview of the different components of the framework that form the possible goals/targets for treatment is presented in Table 1 [83-114].

\section{Hypothesis Testing}

In this framework, a diagnosis comprises the assessment of the two aspects described in the previous paragraphs: (1) the developmental trajectory as a whole, characterised by the developmental profile of processes, and (2) deducing the underlying processing deficit(s) and, from there, identifying treatment targets. Identifying the developmental profile reveals whether specific processes lag behind, which forms the basis for specifying treatment targets. A delayed but balanced profile indicates developmental delay, whereas an unbalanced profile indicates a deviant development [82]. In addition, it needs to be determined whether specific deficits underlie the unbalanced profile, which is especially important for the choice of treatment method.

Thus, development could be delayed or deviant in different ways. Processes and rules/representations can be less accurate, less automated, or slower. Additionally, speech development could start typically until the onset of the speech difficulties, for example, due to increased demands. The assessment and characterisation of the developmental trajectory require standardised and normreferenced speech tasks, as well as language and oral mo- 
Table 1. The processes and rules/representations of the speech production chain that form the possible treatment goals/targets, accompanied by examples of assessments and possible specific task comparisons based on these assessments that address these (note that these are not exhaustive)

\begin{tabular}{|c|c|c|c|c|}
\hline Process & $\begin{array}{l}\text { Rules/ } \\
\text { representations }\end{array}$ & Description & $\begin{array}{l}\text { Example assessment } \\
\text { methods }\end{array}$ & Example task comparisons \\
\hline \multicolumn{5}{|l|}{ Processing } \\
\hline $\begin{array}{l}\text { Phonological } \\
\text { encoding } \\
\text { [e.g., 39-41, 49-51] }\end{array}$ & $\begin{array}{l}\text { Phonological } \\
\text { representations } \\
\text { Phonotactic } \\
\text { rules } \\
\text { Metrical } \\
\text { spell-out }\end{array}$ & $\begin{array}{l}\text { Selection and sequencing of } \\
\text { linguistic/symbolic units that } \\
\text { form goals for speech sounds: } \\
\text { formation of a phonological } \\
\text { phrase }\end{array}$ & $\begin{array}{l}\text { Word and non-word } \\
\text { imitation: phoneme } \\
\text { inventory and error } \\
\text { analysis [e.g., 83-86] }\end{array}$ & $\begin{array}{l}\text { Word vs. non-word imitation (e.g., } \\
\text { a higher segmental error rate in } \\
\text { words indicates poor representation } \\
\text { of lexeme) } \\
\text { Word vs. non-word imitation (e.g., } \\
\text { a higher segmental error rate in } \\
\text { non-words indicates either poor } \\
\text { auditory/memory functions or } \\
\text { poor output assembly) } \\
\text { Word vs. non-word imitation (e.g., } \\
\text { a higher rate of stress attern errors } \\
\text { in non-words indicates either poor } \\
\text { auditory/memory functions or poor } \\
\text { output assembly) }\end{array}$ \\
\hline $\begin{array}{l}\text { Motor planning } \\
\text { [e.g., } 40-42,48,50]\end{array}$ & $\begin{array}{l}\text { Phonemic } \\
\text { mappings }\end{array}$ & $\begin{array}{l}\text { Selection of articulatory } \\
\text { movement goals }\end{array}$ & $\begin{array}{l}\text { Sentence, word, and } \\
\text { non-word imitation: } \\
\text { error analysis and } \\
\text { coarticulation } \\
\text { [e.g., 87-90] }\end{array}$ & $\begin{array}{l}\text { More vs. less complex movements } \\
\text { and context (e.g., higher segmental } \\
\text { error and deletion rates in more } \\
\text { complex movement sequences; } \\
\text { lack of differentiation in anticipatory } \\
\text { coarticulation between consonant } \\
\text { contexts) }\end{array}$ \\
\hline $\begin{array}{l}\text { Motor } \\
\text { programming } \\
{[\text { e.g., } 40,43,45 \text {, }} \\
48,50,53]\end{array}$ & $\begin{array}{l}\text { Systemic } \\
\text { mapping }\end{array}$ & $\begin{array}{l}\text { Implementation in } \\
\text { muscle-specific motor } \\
\text { programmes }\end{array}$ & $\begin{array}{l}\text { Sentence, word, and } \\
\text { non-word imitation: } \\
\text { consistency of repeated } \\
\text { productions [e.g., } \\
\text { 91-94] Adaptation to } \\
\text { external circumstances } \\
\text { (biteblock [95, 96]; lip } \\
\text { tube [97]) }\end{array}$ & $\begin{array}{l}\text { More vs. less complex movements } \\
\text { and context (e.g., higher } \\
\text { inconsistency in longer utterances } \\
\text { and more complex } \\
\text { movement sequences [e.g., } \\
\text { consonant clusters]) }\end{array}$ \\
\hline $\begin{array}{l}\text { Motor execution } \\
\text { [e.g., } 40,43,45 \text {, } \\
48,50,53]\end{array}$ & & $\begin{array}{l}\text { Transmission of neural signals } \\
\text { to peripheral systems and } \\
\text { transformation into } \\
\text { coordinated muscle activity }\end{array}$ & $\begin{array}{l}\text { Diadochokinesis: } \\
\text { maximum repetition } \\
\text { rate, rate variability, } \\
\text { phonation } \\
\text { duration [e.g., 98-103] }\end{array}$ & $\begin{array}{l}\text { More vs. less complex movements } \\
\text { (e.g., /tata/ vs. /sasa/; difficulties in } \\
\text { sensorimotor tuning cause higher } \\
\text { variability in /sasa/) }\end{array}$ \\
\hline \multicolumn{5}{|l|}{ Monitoring } \\
\hline $\begin{array}{l}\text { Internal } \\
\text { self-monitoring } \\
\text { [e.g., 39, 51, 54] }\end{array}$ & $\begin{array}{l}\text { Phonemic } \\
\text { mappings }\end{array}$ & $\begin{array}{l}\text { Detection of incorrectly } \\
\text { planned sounds or movements }\end{array}$ & $\begin{array}{l}\text { Word and non-word } \\
\text { imitation: error } \\
\text { repair [e.g., 104, 105] } \\
\text { Delayed auditory } \\
\text { feedback } \\
\text { [e.g., 106, 107] }\end{array}$ & $\begin{array}{l}\text { Early vs. late/no word uniqueness } \\
\text { point; high vs. low lexical } \\
\text { neighbourhood density; elayed vs. } \\
\text { normal auditory eedback (e.g., } \\
\text { absence of uniqueness point or } \\
\text { neighbourhood density effects on } \\
\text { error repairs indicates poor preverbal } \\
\text { monitoring) }\end{array}$ \\
\hline $\begin{array}{l}\text { External } \\
\text { self-monitoring - } \\
\text { auditory [e.g., } 40 \text {, } \\
43-45,50,53]\end{array}$ & $\begin{array}{l}\text { Systemic } \\
\text { mapping } \\
\text { and phonemic } \\
\text { mappings }\end{array}$ & $\begin{array}{l}\text { Ad hoc adaptation of } \\
\text { articulation and error } \\
\text { correction }\end{array}$ & $\begin{array}{l}\text { Auditory feedback } \\
\text { masking and } \\
\text { perturbation } \\
{[108-112]}\end{array}$ & $\begin{array}{l}\text { Masking vs. no masking (e.g., } \\
\text { reduced vowel contrast in masking } \\
\text { indicates poor phonemic mappings) }\end{array}$ \\
\hline $\begin{array}{l}\text { External } \\
\text { self-monitoring - } \\
\text { somatosensory } \\
{[\text { e.g., } 40,43-45,50,53]}\end{array}$ & $\begin{array}{l}\text { Systemic } \\
\text { mapping }\end{array}$ & $\begin{array}{l}\text { Information about the actual } \\
\text { state of the articulatory } \\
\text { system, ad hoc adaptation of } \\
\text { articulation and } \\
\text { error correction }\end{array}$ & $\begin{array}{l}\text { Somatosensory } \\
\text { feedback masking and } \\
\text { perturbation }[113,114]\end{array}$ & $\begin{array}{l}\text { Masking vs. no-masking } \\
\text { e.g., increased variability in masking } \\
\text { indicates poor phonemic mappings) }\end{array}$ \\
\hline
\end{tabular}


tor tasks [115, see also 116]. ${ }^{1}$ To a large extent, these instruments are available (albeit not for all languages). Identifying the processes involved requires an experimental research methodology that has become available only recently, and still needs to be further developed and refined and subsequently implemented in clinical instruments. In essence, the approach follows the principal ideas of Stackhouse and Wells [12, 121], later advocated by Baker et al. [38], and is very similar in spirit to the Psycholinguistic Assessments of Language Processing in Aphasia (PALPA) [122]. The approach comprises a reiterative process of hypothesis testing by means of objective measurements of speech output in systematically varied tasks under systematically varied conditions. Different speaking tasks and speaking conditions put different demands on different components of the speech production model (Table 1). In the right combination, this enables a demonstration of the processes involved. Based on a specific test result, a hypothesis about the speech impairment is formulated or adjusted, which is then evaluated by means of a subsequent test or condition. Eventually, after a number of steps, this leads to a profile characterising which processes and rules/representations of the speech production chain are involved. Ultimately, a specific diagnosis is established by deducing the underlying deficit(s) based on this profile, in combination with the characterisation of the impairment. A concrete treatment plan can then be drafted to target (or circumvent) the impairment, taking into account other relevant aspects such as age, severity, and individual characteristics and personal interests.

First steps in such profiling of speech production and perception characteristics based on an extensive assessment battery have been successfully made in research applications for diagnostic group assignment for some time [123-125]. Similarly, model-based approaches comprising detailed comparisons of different tasks and/or conditions to specify the underlying speech processing difficulties involved in children with speech impairment are be-

\footnotetext{
${ }^{1}$ Although there is debate about the potential utility of non-speech oral motor tasks $[98,99,116-120]$, they represent an important first step in differential diagnosis investigating the anatomy and (neuromuscular) functionality of the oral motor system. The necessity of non-speech oral motor tasks directly follows from classic definitions of DSD. CAS, for example, is defined as "a neurological childhood (pediatric) speech sound disorder in which the precision and consistency of movements underlying speech are impaired in the absence of neuromuscular deficits (e.g., abnormal reflexes, abnormal tone)" [37, p. 3; emphasis added]. A non-speech oral motor examination offers insight into possible neuromuscular or structural anatomical impairments. Furthermore, Thoonen et al. [98, 99] have shown that diadochokinesis tasks are discriminative between CAS and DD.
}

ing used successfully in experimental studies [108, 110, $126,127]$. A particularly nice example is the recent study by Geronikou and Rees [127], who used a battery of speech production and perception tasks to specify - for each child individually - the underlying speech processing difficulties in four 4.5- to 5.5-year-old children with a PD with very similar speech error patterns. The speech output tasks included picture naming, word repetition, and non-word repetition, while the perception tasks included non-word discrimination and mispronunciation detection. All children showed similar problems in the speech production tasks, but the results showed specific differences in the performance on the perception tasks for these specific target sounds. Two of the children had difficulties in the mispronunciation detection task but not in non-word discrimination, leading the authors to infer that for these children the problem resided in the phonological representations of the target sounds. The other 2 children had no difficulty with either mispronunciation detection or non-word discrimination, suggesting that the target sounds were well specified in the phonological representations but not in the motor representations (phonemic mappings in the terminology of the present paper). As the authors concluded, this makes a fundamental difference for intervention [127].

The example above, as well as the PALPA [122], can be characterised as a neuropsychological approach, comprising the administration of a test battery and deducing from the profile which underlying process(es) is/are disrupted. Such a comprehensive speech profile is the first step towards a process-oriented diagnosis in which underlying deficits are identified. The next step is to directly manipulate speech processes, for instance, by speeding up, masking noise, auditory perturbation, distorting kinaesthetic feedback, or short learning tasks (brief diagnostic therapies). Rather than having to interpret a particular speech profile, which relies on a matched comparison group, in these varying conditions the subject is his or her own control. The required experimental methods are available and are being further developed and fine-tuned in research studies. Slowly but certainly, they are becoming available for use in clinical practice.

\section{Conclusions}

In this paper, we presented a model of speech processing that can serve as a framework for a process-oriented approach to diagnosis and treatment planning of DSD. This process-oriented approach holds important advan- 
tages, in that it offers direct leads for treatment aimed at the specific underlying impairment and adjusted during the course of the speech disorder. Although the diagnostic procedure will be more time-consuming than the current procedures, a more targeted treatment tailored to the specific needs of the individual promises to be more effective and efficient. Moreover, we believe that current and future technological advances in diagnostic instrumentation, such as automated test administration and automated processing and analyses of test performance, will partly eliminate these drawbacks.

Possibly more problematic is that this process-oriented approach requires a different way of thinking by clinical practitioners $[12,33,34,38,40,50,121]$. Speech therapists are generally trained to focus on speech output skills, to think and work according to a framework of diagnostic classification based on behavioural symptoms only and plan treatment according to the corresponding protocol. A change to a practice of hypothesis testing in a psycholinguistic framework requires a different education and training to provide speech therapists with the theoretical background and the clinical skills to utilise and interpret a process-oriented instrument for diagnos- tics and treatment planning [31-33]. The step from a behavioural to a process-oriented diagnostic and treatment planning means, in the words of Baker et al. [38], "reframing the ways in which we understand children's communication problems" (p. 700) [see also 33, 34, 40, 50, 121].

\section{Acknowledgements}

This work was supported by the Netherlands Organization for Scientific Research (NWO-VENI grant 275-89-016 awarded to H.T.), and the National Institutes of Health (National Institute of Deafness and Other Communication Disorders grant K01DC010216 awarded to E.M.).

\section{Statement of Ethics}

The authors have no ethical conflicts to disclose.

\section{Disclosure Statement}

The authors have no conflicts of interest to disclose.

\section{References}

1 Campbell TF. Functional treatment outcomes in young children with motor speech disorders. In: Caruso A, Strand E, editors. Clinical Management of Motor Speech Disorders in Children. New York: Thieme; 1999. pp. 385-96.

2 Conti-Ramsden G, Botting N. Social difficulties and victimization in children with SLI at 11 years of age. J Speech Lang Hear Res. 2004 Feb;47(1):145-61.

3 van Daal J, Verhoeven L, van Balkom H. Behaviour problems in children with language impairment. J Child Psychol Psychiatry. 2007 Nov;48(11):1139-47.

4 McCormack J, McLeod S, McAllister L, Harrison LJ. A systematic review of the association between childhood speech impairment and participation across the lifespan. Int J Speech Lang Pathol. 2009;11(2):155-70.

5 Felsenfeld S, Broen PA, McGue M. A 28-year follow-up of adults with a history of moderate phonological disorder: educational and occupational results. J Speech Hear Res. 1994 Dec; 37(6):1341-53.

6 Snowling MJ, Adams JW, Bishop DV, Stothard SE. Educational attainments of school leavers with a preschool history of speechlanguage impairments. Int J Lang Commun Disord. 2001 Apr-Jun;36(2):173-83.

7 Waring R, Knight R. How should children with speech sound disorders be classified? A review and critical evaluation of current classification systems. Int J Lang Commun Disord. 2013 Jan;48(1):25-40.

8 Lewis BA, Freebairn LA, Hansen AJ, Stein CM, Shriberg LD, Iyengar SK, et al. Dimensions of early speech sound disorders: a factor analytic study. J Commun Disord. 2006 MarApr;39(2):139-57.

9 Shriberg LD, Fourakis M, Hall SD, Karlsson HB, Lohmeier HL, McSweeny JL, et al. Extensions to the Speech Disorders Classification System (SDCS). Clin Linguist Phon. 2010 Oct; 24(10):795-824.

10 Dodd B, editor. Differental Diagnosis and Treatment of Children with Speech Disorder. 2nd ed. London: Whurr; 2005

11 Dodd B. Differential Diagnosis of Pediatric Speech Sound Disorder. Curr Dev Disord Rep. 2014;1(3):189-196.

12 Stackhouse J, Wells B. Children's speech and literacy difficulties: a psycholinguistic framework. Wiley; 1997.

13 Boutsen F. Prosody: an organizing principle for neurogenic speech disorders. Asia Pac J Speech Lang Hear. 2008;11(2):81-7.

14 Kent RD. Models of speech motor control: implications from recent developments in neurophysiological and neurobehavioral science. In: Maassen B, Kent R, Peters HF, et al., editors. Speech Motor Control in Normal and
Disordered Speech. Oxford: Oxford University Press; 2004. pp. 1-28.

15 McNeil MR, Ballard KJ, Duffy J, Wambaugh JL. Apraxia of Speech Theory, Assessment, Differential Diagnosis and Treatment: Past, Present and Future. In: Van Lieshout P, Maassen $\mathrm{B}$, Terband $\mathrm{H}$, editors. Speech Motor Control in normal and disordered speech: $\mathrm{Fu}$ ture developments in theory and methodology. Rockville (MD): American Speech-Language-Hearing Association; 2017.

16 McNeil MR, Pratt SR, Fosset TR. The differential diagnosis of apraxia of speech. In: Maassen B, Kent R, Peters HF, et al., editors. Speech Motor Control in Normal and Disordered Speech. Oxford: Oxford University Press; 2004. pp. 389-414.

17 Weismer G, Kim Y. Classification and Taxonomy of Motor Speech Disorders: What are the Issues? In: Maassen B, Van Lieshout P, editors. Speech motor control: New developments in basic and applied research. Oxford: Oxford University Press; 2010. pp. 229-42.

18 Morgan A, Fisher SE, Scheffer I, Hildebrand M. FOXP2-related speech and language disorders. In: Adam MP, Ardinger HH, Pagon RA, Wallace SE, Bean LJH, Stephens K, et al., editors. GeneReviews ${ }^{\circledR}$ [Internet]. Seattle (WA): University of Washington, Seattle; 2016 [updated $2017 \mathrm{Feb} 2$ ]. 
19 Vernes SC, Newbury DF, Abrahams BS, Winchester L, Nicod J, Groszer M, et al. A functional genetic link between distinct developmental language disorders. N Engl J Med. 2008 Nov;359(22):2337-45.

20 Turner SJ, Mayes AK, Verhoeven A, Mandelstam SA, Morgan AT, Scheffer IE. GRIN2A: an aptly named gene for speech dysfunction. Neurology. 2015 Feb;84(6):586-93.

21 Peter B, Matsushita M, Oda K, Raskind W. De novo microdeletion of BCL11A is associated with severe speech sound disorder. Am J Med Genet A. 2014 Aug;164A(8):2091-6.

22 Peter B, Wijsman EM, Nato AQ Jr, Matsushita MM, Chapman KL, Stanaway IB, et al.; University of Washington Center for Mendelian Genomics. Genetic candidate variants in two multigenerational families with childhood apraxia of speech. PLoS One. 2016 Apr; 11(4):e0153864

23 Newbury DF, Fisher SE, Monaco AP. Recent advances in the genetics of language impairment. Genome Med. 2010 Jan;2(1):6.

24 Newbury DF, Monaco AP. Genetic advances in the study of speech and language disorders. Neuron. 2010 Oct;68(2):309-20.

25 Maassen B. Developmental models of childhood apraxia of speech. In: Bahr RH, Silliman ER, editors. Routledge Handbook of Communication Disorders. New York (NY): Routledge; 2015. pp. 124-33.

26 Ziegler W, Ackermann H. Subcortical contributions to motor speech: phylogenetic, developmental, clinical. Trends Neurosci. 2017 Aug;40(8):458-68.

27 Morgan AT, Su M, Reilly S, Conti-Ramsden G, Connelly A, Liégeois FJ. A Brain Marker for Developmental Speech Disorders. J Pediatr. 2018 Jul;198:234-239.e1.

28 Luders E, Kurth F, Pigdon L, Conti-Ramsden G, Reilly S, Morgan AT. Atypical Callosal Morphology in Children with Speech Sound Disorder. Neuroscience. 2017 Dec;367:211-8.

29 Morgan A, Bonthrone A, Liégeois FJ. Brain basis of childhood speech and language disorders: are we closer to clinically meaningful MRI markers? Curr Opin Pediatr. 2016 Dec; 28(6):725-30

30 Bishop DV, Snowling MJ. Developmental dyslexia and specific language impairment: same or different? Psychol Bull. 2004 Nov; 130(6):858-86

31 Maassen B, Terband H. Process-oriented diagnosis of Childhood and adult Apraxia of Speech (CAS \& AOS). In: Redford MA, editor. Handbook of Speech Production. Malden (MA): Wiley-Blackwell; 2015.

32 Terband H, Maassen B. Spraakontwikkelingsstoornissen: van symptoom- naar procesdiagnostiek. Logopedie en Phoniatrie. 2012; 7-8:229-34.

33 Terband H, Maassen B, Maas E. Toward a model of pediatric speech sound disorders (SSD) for differential diagnosis and therapy planning. In: Van Lieshout P, Maassen B, Terband $\mathrm{H}$, editors. Speech Motor Control in normal and disordered speech: Future devel- opments in theory and methodology. Rockville (MD): American Speech-LanguageHearing Association; 2016.

34 Terband H, Maassen B, Maas E. Klinisch forum: Een procesgerichte aanpak van differentiaaldiagnose en therapieplanning bij spraakontwikkelingsstoornissen. Stem-, Spraaken Taalpathologie. 2016;21:1-31.

35 Maassen B, Nijland L, Terband H. Developmental models of Childhood Apraxia of Speech. In: Maassen B, Van Lieshout P, editors. Speech motor control: New developments in basic and applied research. Oxford: Oxford University Press; 2010. pp. 243-58.

36 Terband H, Maassen B, Guenther FH, Brumberg J. Auditory-motor interactions in pediatric motor speech disorders: neurocomputational modeling of disordered development. J Commun Disord. 2014 Jan-Feb;47:17-33.

37 ASHA. Childhood Apraxia of Speech [technical report]. American Speech-LanguageHearing Association. 2007. Available from: www.asha.org/policy.

38 Baker E, Croot K, McLeod S, Paul R. Psycholinguistic models of speech development and their application to clinical practice. J Speech Lang Hear Res. 2001 Jun;44(3):685-702.

39 Levelt WJ. Speaking: From intention to articulation. Cambridge (MA): MIT Press; 1989.

40 Van der Merwe A. A theoretical framework for the characterization of pathological speech sensorimotor control. In: McNeil MR, editor. Clinical Management of Sensorimotor Speech Disorders. New York: Thieme Medical Publishers Inc; 1997. pp. 1-25.

41 Bohland JW, Bullock D, Guenther FH. Neural representations and mechanisms for the performance of simple speech sequences. J Cogn Neurosci. 2010 Jul;22(7):1504-29.

42 Klapp ST. Reaction time analysis of two types of motor preparation for speech articulation: action as a sequence of chunks. J Mot Behav. 2003 Jun;35(2):135-50

43 Kröger BJ, Kannampuzha J, Neuschaefer-Rube C. Towards a neurocomputational model of speech production and perception. Speech Commun. 2009;51(9):793-809.

44 Hickok G. Computational neuroanatomy of speech production. Nat Rev Neurosci. 2012 Jan;13(2):135-45.

45 Guenther FH. A neural network model of speech acquisition and motor equivalent speech production. Biol Cybern. 1994;72(1): 43-53.

46 Goldstein LM, Fowler CA. Articulatory phonology: A phonology for public language use. In: Schiller NO, Meyer AS, editors. Phonetics and Phonology in Language Comprehension and Production: Differences and Similarities. Berlin: Mouton de Gruyter; 2003. pp. 159207.

47 Price CJ, Crinion JT, Macsweeney M. A generative model of speech production in Broca's and Wernicke's areas. Front Psychol. 2011 Sep;2:237

48 Nam H, Browman C, Goldstein L, Rubin P, Proctor M, Saltzman E. TADA (TAsk Dy- namics Application) manual. New Haven (CT): Haskins Laboratories, Inc.; 2007.

49 Goldrick M, Blumstein SE. Cascading activation from phonological planning to articulatory processes: evidence from tongue twisters. Lang Cogn Process. 2006;21(6):649-83.

50 Van der Merwe A. A theoretical framework for the characterization of pathological speech sensorimotor control. In: McNeil MR, editor. Clinical Management of Sensorimotor Speech Disorders. 2nd ed. New York: Thieme Medical Publishers Inc; 2009. pp. 3-18.

51 Levelt WJ, Roelofs A, Meyer AS. A theory of lexical access in speech production. Behav Brain Sci. 1999 Feb;22(1):1-38.

52 Tilsen S. A dynamical model of hierarchical selection and coordination in speech planning. PLoS One. 2013 Apr;8(4):e62800.

53 Guenther FH, Perkell JS. A neural model of speech production and its application to studies of the role of auditory feedback in speech. In: Maassen B, Kent R, Peters HF, et al., editors. Speech Motor Control in Normal and Disordered Speech. Oxford, UK: Oxford University Press; 2004. pp. 29-50.

54 Nooteboom SG, Quené H. Self-monitoring for speech errors: two-stage detection and repair with and without auditory feedback. J Mem Lang. 2017;95:19-35.

55 Bishop DV. Cognitive neuropsychology and developmental disorders: uncomfortable bedfellows. Q J Exp Psychol A. 1997 Nov; 50(4):899-923.

56 Karmiloff-Smith A. The tortuous route from genes to behavior: a neuroconstructivist approach. Cogn Affect Behav Neurosci. 2006 Mar;6(1):9-17.

57 Karmiloff-Smith A, Scerif G, Ansari D. Double dissociations in developmental disorders? Theoretically misconceived, empirically dubious. Cortex. 2003 Feb;39(1):161-3.

58 Nip IS, Green JR, Marx DB. The co-emergence of cognition, language, and speech motor control in early development: a longitudinal correlation study. J Commun Disord. 2011 Mar-Apr;44(2):149-60.

59 Duffy JR. Motor Speech Disorders: Substrates, Differential Diagnosis, and Management. St Louis (MO): Mosby; 2005.

60 Fletcher SG. Speech production following partial glossectomy. J Speech Hear Disord. 1988 Aug;53(3):232-8.

61 Skelly M, Spector DJ, Donaldson RC, Brodeur A, Paletta FX. Compensatory physiologic phonetics for the glossectomee. J Speech Hear Disord. 1971 Feb;36(1):101-14.

62 Morrish EC. Compensatory articulation in a subject with total glossectomy. Br J Disord Commun. 1988 Apr;23(1):13-22.

63 Morrish L. Compensatory vowel articulation of the glossectomee: acoustic and videofluoroscopic evidence. Br J Disord Commun. 1984 Sep;19(2):125-34.

64 Barry WJ, Timmermann G. Mispronunciations and compensatory movements of tongue-operated patients. Br J Disord Commun. 1985 Apr;20(1):81-90. 
65 Georgian DA, Logemann JA, Fisher HB. Compensatory articulation patterns of a surgically treated oral cancer patient. J Speech Hear Disord. 1982 May;47(2):154-9.

66 Knipfer C, Riemann M, Bocklet T, Noeth E, Schuster M, Sokol B, et al. Speech intelligibility enhancement after maxillary denture treatment and its impact on quality of life. Int J Prosthodont. 2014 Jan-Feb;27(1):61-9.

67 Hamlet SL, Stone M. Speech adaptation to dental prostheses: the former lisper. J Prosthet Dent. 1982 May;47(5):564-9.

68 Hörschgen J, Wisser W, Berger R, Lotzmann $\mathrm{U}$. The influence of major connectors of partial dentures of phonation: an instrumental analysis of speech. Folia Phoniatr Logop. 2004 May-Jun;56(3):144-56.

69 Laine T, Jaroma M, Linnasalo AL. Relationships between interincisal occlusion and articulatory components of speech. Folia Phoniatr (Basel). 1987;39(2):78-86.

70 Smith A, Goffman L. Interaction of motor and language factors in the development of speech production. In: Maassen B, Kent R, Peters HF, et al., editors. Speech Motor Control in Normal and Disordered Speech. Oxford, UK: Oxford University Press; 2004. pp. 22552.

71 Terband H, Maassen B. Speech motor development in childhood apraxia of speech: generating testable hypotheses by neurocomputational modeling. Folia Phoniatr Logop. 2010;62(3):134-42.

72 Strand EA, McCauley RJ, Weigand SD, Stoeckel RE, Baas BS. A motor speech assessment for children with severe speech disorders: reliability and validity evidence. J Speech Lang Hear Res. 2013 Apr;56(2):505-20.

73 Chapman KL. Phonologic processes in children with cleft palate. Cleft Palate Craniofac J. 1993 Jan;30(1):64-72.

74 Konst EM, Rietveld T, Peters HF, Prahl-Andersen B. Phonological development of toddlers with unilateral cleft lip and palate who were treated with and without infant orthopedics: a randomized clinical trial. Cleft Palate Craniofac J. 2003 Jan;40(1):32-9.

75 van Lieshout PH, Rutjens CA, Spauwen PH. The dynamics of interlip coupling in speakers with a repaired unilateral cleft-lip history. J Speech Lang Hear Res. 2002 Feb;45(1):5-19.

76 Whitehill TL, Francis AL, Ching CK. Perception of place of articulation by children with cleft palate and posterior placement. J Speech Lang Hear Res. 2003 Apr;46(2):451-61.

77 Crary MA, Landess S, Towne R. Phonological error patterns in developmental verbal dyspraxia. J Clin Neuropsychol. 1984 May;6(2): $157-70$.

78 Marion MJ, Sussman HM, Marquardt TP. The perception and production of rhyme in normal and developmentally apraxic children. J Commun Disord. 1993 Sep;26(3):12960.

79 Shriberg LD, Strand EA, Fourakis M, Jakielski KJ, Hall SD, Karlsson HB, et al. A diagnostic marker to discriminate childhood apraxia of speech from speech delay: introduction. J Speech Lang Hear Res. 2017 Apr;60(4):S10945

80 Dodd B, Ttofari-Eecen K, Brommeyer K, Ng K, Reilly S, Morgan A. Delayed and disordered development of articulation and phonology between four and seven years. Child Lang Teach Ther. 2018;34(2):87-99.

81 Dodd B. Differentiating speech delay from disorder: does it matter? Top Lang Disord. 2011;31(2):96-111.

82 Curtiss S, Katz W, Tallal P. Delay versus deviance in the language acquisition of languageimpaired children. J Speech Hear Res. 1992 Apr;35(2):373-83.

83 Wilshire CE, McCarthy RA. Experimental Investigations of an Impairment in Phonological Encoding. Cogn Neuropsychol. 1996; 13(7):1059-98.

84 Munson B, Krause MO. Phonological encoding in speech-sound disorder: evidence from a cross-modal priming experiment. Int J Lang Commun Disord. 2017 May;52(3): 285-300.

85 Munson B, Baylis AL, Krause MO, Yim D. Representation and access in phonological impairment. Lab Phonol. 2010;10:381-404.

86 Seiger-Gardner L, Brooks PJ. Effects of onsetand rhyme-related distractors on phonological processing in children with specific language impairment. J Speech Lang Hear Res. 2008 Oct;51(5):1263-81.

87 Bahr R. Differential diagnosis of severe speech disorders using speech gestures. Top Lang Disord. 2005;25(3):254-65.

88 Nijland L, Maassen B, Van der Meulen S, Gabreels F, Kraaimaat FW, Schreuder R. Coarticulation patterns in children with developmental apraxia of speech. Clin Linguist Phon. 2002 Sep;16(6):461-83.

89 Nijland L, Maassen B, Van Der Meulen S, Gabreëls F, Kraaimaat FW, Schreuder R. Planning of syllables in children with developmental apraxia of speech. Clin Linguist Phon. 2003 Jan-Feb;17(1):1-24.

90 Terband H. Deviant coarticulation in childhood apraxia of speech (CAS) does not include hyperarticulation. In: Maassen B, Terband $\mathrm{H}$, van Lieshout $\mathrm{P}$, editors. 7th International Conference on Speech Motor Control; 2017 July 5-7; Groningen, the Netherlands. Stem-, Spraak- en Taalpathologie; 2017.

91 Iuzzini-Seigel J, Hogan TP, Green JR. Speech inconsistency in children with childhood apraxia of speech, language impairment, and speech delay: depends on the stimuli. J Speech Lang Hear Res. 2017 May;60(5): 1194-210.

92 Marquardt TP, Jacks A, Davis BL. Token-totoken variability in developmental apraxia of speech: three longitudinal case studies. Clin Linguist Phon. 2004 Mar;18(2):127-44.

93 Preston JL, Koenig LL. Phonetic variability in residual speech sound disorders: exploration of subtypes. Top Lang Disord. 2011 Apr; 31(2):168-84.
94 Maner KJ, Smith A, Grayson L. Influences of utterance length and complexity on speech motor performance in children and adults. J Speech Lang Hear Res. 2000 Apr;43(2):56073.

95 Nijland L, Maassen B, van der Meulen S. Evidence of motor programming deficits in children diagnosed with DAS. J Speech Lang Hear Res. 2003 Apr;46(2):437-50.

96 Namasivayam AK, van Lieshout P, De Nil L. Bite-block perturbation in people who stutter: immediate compensatory and delayed adaptive processes. J Commun Disord. 2008 Jul-Aug;41(4):372-94.

97 Ménard L, Perrier P, Aubin JM, Savariaux C, Thibeault M. Compensation strategies for a lip-tube perturbation of French $[\mathrm{u}]$ : an acoustic and perceptual study of 4-year-old children. J Acoust Soc Am. 2008 Aug;124(2): 1192-206

98 Thoonen G, Maassen B, Gabrieëls F, Schreuder R. Validity of maximum performance tasks to diagnose motor speech disorders in children. Clin Linguist Phon. 1999;13(1):1-23.

99 Thoonen G, Maassen B, Wit J, Gabrieëls F, Schreuder R. The integrated use of maximum performance tasks in differential diagnostic evaluations among children with motor speech disorders. Clin Linguist Phon. 1996;10(4):311-36.

100 Ziegler W. Task-related factors in oral motor control: speech and oral diadochokinesis in dysarthria and apraxia of speech. Brain Lang. 2002 Mar;80(3):556-75.

101 Ackermann H, Hertrich I, Hehr T. Oral diadochokinesis in neurological dysarthrias. Folia Phoniatr Logop. 1995;47(1):15-23.

102 Van Brenk F, Lowit A. The relationship between acoustic indices of speech motor control variability and other measures of speech performance in dysarthria. J Med SpeechLang Pathol. 2012;20:24-9.

103 Diepeveen S, van Haaften L, Terband H, et al. A standardized protocol for Maximum Repetition Rate assessment in children. Folia Phoniatr Logop, under review.

104 Corley M, Brocklehurst PH, Moat HS. Error biases in inner and overt speech: evidence from tongue twisters. J Exp Psychol Learn Mem Cogn. 2011 Jan;37(1):162-75.

105 Coalson GA, Byrd CT, Kuylen A. Uniqueness Point Effects during Speech Planning in Adults Who Do and Do Not Stutter. Folia Phoniatr Logop. 2017;69(5-6):191-208.

106 Siegel GM, Fehst CA, Garber SR, Pick HL Jr. Delayed auditory feedback with children. J Speech Hear Res. 1980 Dec;23(4):802-13.

107 Yeni-Komshian G, Chase RA, Mobley RL. The development of auditory feedback monitoring. II. Delayed auditory feedback studies on the speech of children between two and three years of age. J Speech Hear Res. 1968 Jun;11(2):307-15.

108 Iuzzini-Seigel J, Hogan TP, Guarino AJ, Green JR. Reliance on auditory feedback in children with childhood apraxia of speech. J Commun Disord. 2015 Mar-Apr;54:32-42. 
109 Maas E, Mailend ML, Guenther FH. Feedforward and feedback control in apraxia of speech: effects of noise masking on vowel production. J Speech Lang Hear Res. 2015 Apr;58(2):185-200.

110 Terband H, van Brenk F, van Doornik-van der Zee A. Auditory feedback perturbation in children with developmental speech sound disorders. J Commun Disord. 2014 Sep-Oct;51:64-77.

111 Jacks A, Haley KL. Auditory masking effects on speech fluency in apraxia of speech and aphasia: comparison to altered auditory feedback. J Speech Lang Hear Res. 2015 Dec; 58(6):1670-86.

112 Daliri A, Wieland EA, Cai S, Guenther FH, Chang SE. Auditory-motor adaptation is reduced in adults who stutter but not in children who stutter. Dev Sci. 2018 Mar; 21(2):e12521.

113 Loucks TM, De Nil LF. The effects of masseter tendon vibration on nonspeech oral movements and vowel gestures. J Speech Lang Hear Res. 2001 Apr;44(2):306-16.

114 Namasivayam AK, van Lieshout P, McIlroy WE, De Nil L. Sensory feedback dependence hypothesis in persons who stutter. Hum Mov Sci. 2009 Dec;28(6):688-707.
115 ASHA. Speech-language pathology medical review guidelines: American Speech-Language-Hearing Association. 2011. Available from: www.asha.org/policy.

116 Kent RD. Nonspeech Oral Movements and Oral Motor Disorders: A Narrative Review. Am J Speech Lang Pathol. 2015 Nov;24(4): 763-89.

117 Maas E. Speech and nonspeech: what are we talking about? Int J Speech Lang Pathol. 2017 Aug; 19(4):345-59.

118 Staiger A, Schölderle T, Brendel B, Bötzel K, Ziegler W. Oral motor abilities are task dependent: a factor analytic approach to performance rate. J Mot Behav. 2017 Sep-Oct; 49(5):482-93.

119 Weismer G. Philosophy of research in motor speech disorders. Clin Linguist Phon. 2006 Jul;20(5):315-49.

120 Ziegler W, Ackermann H. Neuromotor speech impairment: it's all in the talking. Folia Phoniatr Logop. 2013;65(2):55-67.
121 Stackhouse J, Wells B. Psycholinguistic assessment of developmental speech disorders. Eur J Disord Commun. 1993;28(4): $331-48$.

122 Kay J, Lesser R, Coltheart M. PALPA: Psycholinguistic Assessments of Language Processing in Aphasia. Psychology Press; 2009.

123 Terband H, Maassen B, van Lieshout P, Nijland L. Stability and composition of functional synergies for speech movements in children with developmental speech disorders. J Commun Disord. 2011 Jan-Feb; 44(1):59-74.

124 Nijland L. Speech perception in children with speech output disorders. Clin Linguist Phon. 2009 Mar;23(3):222-39.

125 Nijland L, Terband H, Maassen B. Cognitive functions in childhood apraxia of speech. J Speech Lang Hear Res. 2015 Jun;58(3):55065

126 Terband H, Spruit M, Maassen B. Speech Impairment in Boys With Fetal Alcohol Spectrum Disorders. Am J Speech Lang Pathol. 2018 Nov;27(4):1405-25.

127 Geronikou E, Rees R. Psycholinguistic profiling reveals underlying impairments for Greek children with speech disorders. Child Lang Teach Ther. 2016;32(1):95-110. 